economically beneficial.

There is no doubt that "virtuous and talented men" are state sustaining elements. However, if Vietnam is to take a great leap forward in developing its educational system it must choose the proper strategy of hardware and software development to produce graduates with the skills and qualifications needed to survive in the new market-oriented environment.

\section{The United Arab Emirates and the Branch Campus Gold Rush}

\section{KeVIN SCHOEPP}

Kevin Schoepp is Assistant Director of the Abu Dhabi Campuses of Zayed University in the United Arab Emirates and a doctoral student in higher education leadership at the University of Calgary, Canada. E-mail: kevin.schoepp@zu.ac.ae.

$\mathrm{T}$ The fairly new higher education system in the United Arab Emirates is experiencing accelerated growth. The country opened its first university in 1976, established its Ministry of Higher Education in I992, and began full-time licensing and accrediting of higher education in 2000. Many foreign institutions have opened branch campuses. This expansion's frenetic pace has presented both opportunity and peril for the nation and its students.

\section{EXISTING BRANCHES}

Branch campuses have opened throughout this tiny nation from the high-profile city of Dubai to the little-known enclave, of Ras Al Khaimah. However, the government of Dubai, with its market-driven approach, has certainly been at the forefront of the branch-campus movement in the United Arab Emirates. It has done this through the establishment of two education free zones, which often provide facilities, offer subsidies, and bypass the federal higher education accreditation system. Of the two free zones, Knowledge Village has been in operation since 2003, while its successor, International Academic City, was established in 2007. International universities such as the University of Wollongong, University of Exeter, St. Petersburg State University of Engineering \& Economics, and, most prominently, Michigan State University, have all been attracted to what has been called a branch campus gold rush. Not to be outdone, the Emirate of Ras Al Khaimah has an education free zone that includes the University of Bolton, the University of Pune, and, for a little while longer, George Mason University. Branch campus supporters claim that the large number of institutions in Dubai and Ras Al Khaimah are beginning to create a culture of academia and that some are transitioning to a more comprehensive model, including research. Nevertheless, it is within these two emirates, with their limited government support and market-driven approaches, that cracks are beginning to appear in the branch campus façade.

As a newer approach to internationalization, the government of Abu Dhabi has also begun to actively pursue high-profile institutional partnerships. In contrast to other emirates, Abu Dhabi has generally funded the branches and presided in a far more measured and exclusive manner. Regarded as the richest city in the world, it is assumed to possess the financial power to fund branch campuses. The two major partnerships at this time are with New York University and the ParisSorbonne University. The government recently gifted New York University US\$50 million as a commitment to launching a branch campus in the capital. The Paris-Sorbonne branch campus is also government financed and will have a prestigious landmark facility built. The latest candidates for branch campuses include the University of Oxford and the American women's liberal arts college, Bryn Mawr. Not all Abu Dhabi branch campus overtures have been successful, however. Even with full financial support, Yale dropped plans in 2008 to open an arts institute because of a dispute concerning the degrees being offered. Whether the more measured approach taken by Abu Dhabi will fare any better than the market-driven model employed by Ras Al Khaimah and Dubai remains to be seen. Though Abu Dhabi's funding seems sound, it too may become stretched in these times of global economic uncertainty and reduced petrochemical revenue.

\section{Closures}

As the first high-profile casualty of this branch campus gold rush, the University of Southern Queensland closed its doors in 2005, after just one year. With the recent announcement of George Mason's closing after only three years, a shadow has been cast over the entire branch-campus industry in the United Arab Emirates. At last count more than 55 universities were operating in a country with a population of only 4.5 million. Furthermore, a scan of programs on offer indicates that far too many institutions are now looking to the Americanstyle MBA as their way into an already overcrowded marketplace-for example, the University of Pune. One begins to question the motives of many of these institutions - if they have the development of the country at heart, especially when closures and abandonments occur. More often than not, the allure of financial gain for the home campus seems to be a major driving force for establishing any branches.

Continually, the mantra of branch campuses in the United Arab Emirates describes them as committed to the country, meeting the diverse needs of the student population, and understanding what it takes to succeed in the region. These claims have generally been followed up by overinflated predictions for the size of the initial student intake, the potential for subsequent growth, and the language proficiency of regional 
students. George Mason, for example, was predicting nearly 200 students at launch but had less than 40. Paris-Sorbonne's growth has similarly been modest, with only 235 students in the bachelor's degree program after three years and the offering of a master's program to a single student.

Once a branch campus is opened, the next phase consists of denials that the low numbers of students registered and the extremely high percentage of new registrants in languagetraining programs are negative or unexpected. The numbers, if publicized, are actually championed as evidence that standards are being upheld and the institution is steadfast in its commitment to slow and steady growth of benefit to the students and the region. Both Michigan State and the Paris-Sorbonne have recently made these claims. Given that so many other institutions have opened branch campuses, competition for students has increased sharply and there are never as many as originally anticipated. The financial realities at a branch campus begins to erode the initial exuberance that led to its ill-fated conception. Pledges had been made that the branch campus, while not driven by profit, would certainly not drain resources from the home campus.

\section{Branch campus supporters claim that the large number of institutions in Dubai and Ras Al Khaimah are beginning to create a culture of aca- demia and that some are transitioning to a more comprehensive model, including research.}

Pressures mount to increase enrollments because tuitionpaying students are the foundation on which the branch campus is built. A foreign partner who was subsidizing a branch campus might begin to pressure the university to attempt such an increase as losses continue to mount. However, the university needs to maintain its entrance requirements to remain credible and accredited in the eyes of the skeptical faculty and the regional accrediting body back home. Eventually the weight of the expanding debt and poor enrollment levels destines the branch campus to the pages of the history books.

The home institution's administration argues that issues beyond its control such as a dispute with an unruly partner or even the global financial crisis made closure unavoidable. The University of Southern Queensland and George Mason put forth these respective arguments. It was not that they did not exercise their due diligence, were blinded by the bright lights of Dubai, or feared missing the branch-campus gold rush. Theirs was a noble attempt couched in the belief that they were offering an olive branch to the people of the region, only to have a force majeure halt the program's progress. They are truly sorry that an opportunity for students to receive an accredited foreign degree, while never leaving the region, has been removed a few years and thousands of dollars later.

\section{CONCLUSION}

The rapid growth of higher education in the United Arab Emirates has brought about an explosion in the branch-campus phenomena. Like other gold rushes, the hurried expansion of branch campuses will lead to a few successes and a number of failures. Though George Mason is by far the most-high-profile casualty in the current system, it was not the first and will not be the last. Failures cause reverberations throughout the region. Skeptics revel, students suffer, and the United Arab Emirates is worse off than when it opened its doors.

\section{Turkmenistan: Fixing Decades of Damage}

\section{Martha Merrill}

Martha Merrill is associate professor of higher education at Kent State University. She worked on university reform issues in Kyrgyzstan from 1996 to 2001.E-mail: mmerril@kent.edu.

For I8 years, until the death of its dictator Saparmurad F Niyazov on December 2I, 2006, Turkmenistan had been one of the most isolated countries in the world. Yet, in 2008 , an audit of the natural gas reserves in Turkmenistan indicated the amount available as substantially larger than most observers had anticipated and could put Turkmenistan among the top five sources of natural gas in the world. With businesses and consumers around the globe clamoring for energy, such reserves give Turkmenistan substantial political and economic clout, but only if the gas is sold abroad. However, doing so, perhaps more than is broadly understood in Turkmenistan, would involve major changes throughout the society. The new president, Gurbanguly Berdymukhammedov, confronts many challenges and choices in deciding if and how to restructure that society. One critical field is higher education.

\section{The Niyazov Years: Decimation}

During the Niyazov years, the educational system in Turkmenistan was decimated. As David Lewis, the former director of the International Crisis Group's Project in Central Asia has written, "Turkmenistan is one of the few states in which a deliberate policy of reducing education has been used to produce a politically compliant and educationally backward population."

Niyazov cut the number of years of elementary and secondary school from io to 9, thus ensuring that no locally educated students were prepared for higher education outside of Turkmenistan. Given that students had to spend hours memo- 